\title{
HUBUNGAN WAKTU TUNGGU PINDAH (BOARDING TIME) PASIEN TRAUMA LEVEL 1 DAN 2 DENGAN KEJADIAN KEMATIAN DI IGD RSUP SANGLAH DENPASAR
}

\author{
Ngakan Nyoman Rai Bawa*, I Dewa Agung Ketut Sudarsana, Made Duita \\ STIKes Wira Medika PPNI Bali, Indonesia \\ *)E-mail: ngakanr41@gmail.com
}

\begin{abstract}
ABSTRAK
Latar belakang: Pelayanan yang cepat dan tepat sangat dibutuhkan di dalam pelayanan Instalasi Gawat Darurat (IGD). Pelayanan di IGD dapat terhambat jika kondisi di dalam IGD penuh dengan pasien yang disebabkan oleh tidak sesuainya jumlah pasien yang berkunjung ke IGD dengan tempat tidur yang ada di IGD dan ruang rawat inap penuh. Hal tersebut dapat mengakibatkan waktu tunggu pasien yang lama untuk pindah ke ruangan yang berdampak terhadap keselamatan dan nyawa pasien itu sendiri. Tujuan: Penelitian ini bertujuan untuk mengetahui hubungan waktu tunggu pindah (boarding time) pasien trauma level 1 dan 2 dengan kejadian kematian. Metode: Penelitian ini merupakan noneksperimen, dengan rancangan observasional analitik dengan pendekatan cross sectional. Teknik pengambilan sampel dengan cara non probability sampling yaitu consecutive sampling, sebanyak 41 orang. Instrumen yang digunakan lembar observasi dan rekam medik pasien. Analisis data dilakukan dengan menggunakan uji Chi-Square. Hasil: Hasil analisis dapat diperoleh nilai $\alpha=0,021, \mathrm{X}^{2}=5,331$ dan odds ratio 4,571 . Ada hubungan waktu tunggu pindah (boarding time) pasien trauma level 1 dan 2 dengan kejadian kematian dengan arah korelasi positif dan memiliki risiko kematian 4,571 lipat, sekurang-kurangnya memiliki risiko kematian sebesar 1,089 kali lipat dan paling besar berisiko kematian sebesar 17,157 kali lipat. Kesimpulan: Banyak faktor yang menyebabkan kematian pasien di IGD, salah satunya adalah waktu tunggu (boarding time) pasien yang terlalu lama.
\end{abstract}

Kata kunci: IGD, waktu tunggu pindah (boarding time), kejadian kematian

The Correlation of Boarding Time of Trauma Patient Level 1 and 2 with Mortality Event in Emergency Department Sanglah Hospital Denpasar

\begin{abstract}
Background: Rapid and effective response are highly demand in the Emergency Department. Delayed emergency services may happen if the patients' occupancy is full, it occurred due to amount of patients are higher than the beds available in the emergency room and in wards. Thus, it may lead to longer time needed for patients movement to ward (boarding time) effecting the patient's safety nevertheless threatening the patient's life itself. Objective: The purpose of this study was to determine the correlation between boarding time of trauma patient level 1 and 2 with mortality event. Method: This study was non-exsperimen, observasional analitik design with cross sectional approach. Sampling technique used non-probability sampling with consecutive sampling, as many as 41 people. The instrument used was an observation and the patient medical record. Data analysis was done using Chi-Square test. Results: Results of analysis can be obtained by value $\alpha=0,021$ and $X^{2}=5,331$ and odds ratio 4,571. There is a correlation between Boarding time of trauma patient level 1 and 2 with mortality event with positive correlation direction with risk of mortality 4,571, odds ratio lower bound mortality risk 1,089 and upper bound 17,157. Conclusion: There was many factors that caused death in Emergency Departement one of them was too long boarding time patient.
\end{abstract}

Keywords: emergency department, boarding time, mortality event 


\section{LATAR BELAKANG}

Pelayanan yang cepat dan tepat sangat dibutuhkan di dalam pelayanan Instalasi Gawat Darurat (IGD). Pelayanan di IGD dapat terhambat jika kondisi di dalam IGD penuh dengan pasien. Kondisi ini disebabkan oleh tidak sesuainya jumlah pasien yang berkunjung ke IGD dengan tempat tidur yang ada di IGD dan ruang rawat inap penuh. Hal tersebut dapat mengakibatkan waktu tunggu pasien yang lama untuk pindah ke ruangan atau boarding time memanjang yang seharusnya tidak lebih dari 2 jam setelah diputuskan untuk rawat inap (Forero \& Hilman, 2011). Hal ini tentunya berdampak terhadap keselamatan pasien dan membahayakan nyawa pasien itu sendiri. Adanya boarding time memanjang di IGD berhubungan dengan tingkat kematian, semakin lama boarding time pasien di IGD dapat menyebabkan semakin tinggi risiko kematian pasien.

Berdasarkan penelitian yang dilaksanakan Singer, dkk (2011), boarding time yang terjadi di salah satu IGD Rumah Sakit pendidikan di Amerika dengan rata-rata 5,6-7,8 jam, pada tahun 2011, dari 41.256 kunjungan dalam 1 tahun. Hal ini juga diperkuat oleh hasil penelitian Damayanti, Sutono, \& Darsih (2017) yang menyatakan bahwa untuk kategori pasien stagnan paling banyak berada di IGD Rumah Sakit Umum Pusat (RSUP) Dr. Sardjito selama 2-4 jam. Meningkatnya kunjungan dan rujukan pasien ke IGD Rumah Sakit menyebabkan lamanya boarding time pasien tersebut. Kondisi IGD seperti ini akan berdampak terhadap kondisi pasien yang semakin buruk karena tidak ditangani secara cepat dan tepat, adanya penundaan pemberian obat penting karena keterbatasan tenaga kesehatan dan komplikasi penyakit yang membahayakan nyawa pasien.

RSUP Sanglah Denpasar sebagai rumah sakit rujukan Indonesia Timur, merupakan salah satu rumah sakit yang memiliki IGD dengan jumlah kunjungan pasien baru dan lama sebanyak 155 orang setiap harinya. Hal ini menjadi salah satu hal yang menyebabkan kondisi di IGD menjadi semakin penuh. Berdasarkan kebijakan RSUP Sanglah Denpasar tahun 2012 tentang waktu tunggu pindah dilakukan setelah pasien di asessment sampai mendapatkan ruangan ditargetkan $\leq 2$ jam. Pasien yang berada di IGD RSUP Sanglah rata-rata memiliki waktu tunggu pasien $>2$ jam. Hal ini dibuktikan dengan sisa pasien yang dinyatakan rawat inap, masih menunggu ruang rawat di IGD yang dicatat dalam laporan harian IGD.

Berdasarkan hasil studi pendahuluan tanggal 28 Februari 2016 dengan teknik wawancara dengan salah satu perawat dan laporan kegiatan bulanan IGD RSUP Sanglah Denpasar bahwa jumlah tempat tidur yang ada sebanyak 40 bed dan 10 bed cadangan. Data kunjungan pasien di IGD RSUP Sanglah dari akhir Juli 2015-Desember 2015 sebanyak 19.443 pasien, dengan rata-rata kunjungan perbulan sebanyak 3.241 pasien. Berdasarkan data tersebut, tercatat selama 6 bulan sebanyak 4.526 pasien mengalami boarding time $>2$ jam, rata-rata perbulan 754 pasien dengan jumlah pasien trauma level 1 dan 2 sebanyak 45 pasien atau sekitar 10\% dari total kunjungan perbulan.

Dari rata-rata kunjungan pasien ke IGD RSUP Sanglah setiap bulan, sebagian besar didominasi oleh kasus trauma sebanyak 648 pasien (86\%), yang membutuhkan ruang intensif sebanyak 130 pasien (20\%). Sebanyak $20 \%$ pasien trauma yang membutuhkan ruang intensif tersebut, angka kematiannya adalah $16 \%$ atau sekitar 21 pasien perbulan.

Angka kematian di IGD Rumah Sakit merupakan salah satu indikator kinerja rumah sakit. Meningkatnya jumlah boarding time pasien di IGD tentunya akan berdampak langsung terhadap keselamatan pasien. 
Boarding time pasien yang seharusnya $\leq 2$ jam menjadi salah satu tolok ukur sehingga tidak terjadi hal-hal yang bisa membahayakan nyawa pasien. Melihat pentingnya keselamatan pasien dan dampak negatif yang ditimbulkan dengan lamanya waktu tunggu pindah (boarding time) di IGD RSUP Sanglah sehingga membahayakan nyawa pasien itu sendiri, maka perlu diteliti apakah ada hubungan waktu tunggu pindah (boarding time) pasien trauma level 1 dan 2 dengan kejadian kematian di IGD RSUP Sanglah Denpasar Tahun 2016.

\section{METODE}

Penelitian ini merupakan penelitian non eksperimen dengan rancangan penelitian observasional analitik dan model pendekatan subyek yang digunakan cross sectional. Jumlah sampel penelitian ini adalah 41 pasien sesuai dengan kriteria inklusi dan kriteria eksklusi di Triage Bedah RSUP Sanglah Denpasar mulai Tanggal 1 April sampai dengan 31 Mei 2016.

Kriteria inklusi dalam penelitian ini adalah pasien trauma dengan triage level 1 dan level 2 dan keluarga pasien yang bersedia keluarganya menjadi responden. Kriteria eksklusinya adalah Pasien DOA (Death on Arrival). Variabel bebas (Independent Variable) penelitian ini adalah waktu tunggu pasien pindah (Boarding Time) pasien trauma level 1 dan 2 yaitu rentang waktu yang dibutuhkan sejak pasien trauma level 1 dan 2 dinyatakan pindah ke ruang intensif sampai pasien pindah ke ruangan tersebut, yang diukur dengan ukuran waktu jam. Variabel terikat (Dependent Variable) adalah kejadian kematian yaitu suatu keadaan dimana pasien sudah dinyatakan meninggal oleh dokter dan atau dinyatakan DNAR disetujui dalam rapat team dokter yang merawat yang terdiri dari 3 orang dokter yaitu spesialis Anestesiologi, Spesialis Neurologi dan DPJP yang dicatat di rekam medis pasien. Penelitian ini menggunakan teknik nonprobability sampling dengan jenis consecutive sampling.

Instrumen yang digunakan adalah lembar observasi dan catatan rekam medik pasien. Data dianalisis menggunakan analisis univariat dengan menampilkan dalam bentuk tabel frekuensi dan gambar, dijelaskan dalam bentuk narasi serta menggunakan Analisis Bivariat yaitu menganalisis hubungan antara dua variabel yang diduga berkorelasi.

Surat keterangan Kelaikan Etik dikeluarkan Bagian Litbang FK UNUD/ RSUP Sanglah Denpasar, kemudian surat disampaikan ke bagian Diklit RSUP Sanglah Denpasar. Surat permohonan ijin penelitian dari Dinas Perizinan dan Penanaman Modal Provinsi Bali diserahkan kepada Bagian Litbang FK UNUD/ RSUP Sanglah Denpasar dengan melampirkan proposal asli, untuk mendapatkan kelaikan etik.

\section{HASIL}

Berdasarkan tabel 1, didapatkan bahwa sebagian besar responden adalah laki-laki yaitu sebanyak 29 orang $(70,7 \%)$, sebagian besar responden adalah pasien trauma level 1 yaitu sebanyak 22 orang $(53,7 \%)$, sebagian besar responden dengan trauma kepala yaitu sebanyak 30 orang $(73,2 \%)$, waktu tunggu pindah (boarding time) pasien trauma level 1 dan 2 sebagian besar $>2$ jam, yaitu sebanyak 23 orang $(56,1 \%)$, dan bahwa kematian pada pasien trauma level 1 dan 2 sebagian besar terjadi, yaitu sebanyak 22 orang $(53,7 \%)$.

Berdasarkan tabel 2, didapatkan bahwa waktu tunggu pindah (boarding time) $\leq 2$ jam pada pasien trauma level 1 dan 2 tidak mengalami kematian sebanyak 12 orang $(66,7 \%)$ sedangkan waktu tunggu pindah (boarding time) $>2$ jam pada pasien trauma level 1 dan 2, mengalami kematian sebanyak 16 orang $(69,6 \%)$. Dari hasil uji 
Chi-Square $\left(\mathrm{X}^{2}\right)$, didapatkan $\mathrm{X}^{2}$ hitung 5,331 yang lebih besar dari nilai $X^{2}$ tabel yaitu $3,841(\mathrm{df}=1)$ dengan nilai signifikansi lebih kecil dari alfa 0,05 ( $\alpha=5 \%$ ) yaitu 0,021. Ini berarti $\mathrm{H} 0$ ditolak dan Ha diterima, maka ada hubungan yang bermakna antara waktu tunggu pindah (boarding time) pasien trauma level 1 dan 2 dengan kejadian kematian di IGD RSUP Sanglah Denpasar (hasil Chi-Square terlampir). Waktu tunggu pindah (boarding time) $>2$ jam pada pasien trauma level 1 dan 2, berisiko mengalami kematian. Berdasarkan pengitungan Odds Ratio didapatkan sebesar 4,571 (tabel 3).

\section{DISKUSI}

Hasil penelitian ini menunjukkan ada hubungan waktu tunggu pindah (boarding time) pasien trauma level 1 dan 2 dengan kejadian kematian dengan arah korelasi positif. Besarnya risiko kematian pada pasien trauma level 1 dan 2 yang memiliki waktu tunggu pindah (boarding time) $>2$ jam sebesar 4,571 kali lipat dibandingkan pasien trauma level 1 dan 2 yang memiliki waktu tunggu pindah (boarding time) $\leq 2$ jam. Setidaknya pasien trauma level 1 dan 2 yang memiliki waktu tunggu pindah (boarding time) $>2$ jam, sekurang-kurangnya memiliki risiko kematian sebesar 1,089 kali lipat dan paling besar berisiko kematian sebesar 17,157 kali lipat. Hasil penelitian ini sesuai dengan hasil penelitian yang dilakukan oleh Forero \& Hilman (2011) di salah satu rumah Sakit terbesar di Amerika Serikat yang menunjukkan bahwa adanya hubungan yang bermakna antara waktu tunggu pindah (boarding time) pasien dengan angka kematian dan lamanya LOS (Length of Stay) pasien di Rumah Sakit.

Waktu tunggu pindah (boarding time) pasien yang lama ternyata ada hubungan terhadap dampak negatif yang ditimbulkan, salah satunya adalah kematian. Beberapa pernyataan yang bisa mendukung hal ini adalah kondisi IGD yang penuh dengan pasien sedangkan tenaga perawat yang tidak sebanding dengan jumlah pasien sehingga sedikit waktu yang dimiliki untuk merawat dan memonitoring pasien yang butuh pengawasan ketat. Hal ini juga didukung oleh beberapa pasien yang datang dalam kondisi kritis dan memerlukan ruang intensif setelah dilakukan resusitasi sedangkan ruang intensif terisi penuh. Pelayanan medis juga tidak begitu optimal karena keterbatasan fasilitas pendukung sehingga evaluasi ulang terhadap pasien yang perlu observasi ketat kadang terlupakan. Banyaknya pasien baru yang datang juga menyebabkan keterlambatan pemberian obat-obatan sesuai waktu yang membutuhkan perhatian khusus (Forero \& Hilman, 2011).

Meningkatnya waktu tunggu pindah (boarding time) pasien di IGD RSUP Sanglah menimbulkan beberapa dampak yang tentunya akan berpengaruh terhadap keselamatan pasien itu sendiri. RSUP Sanglah sudah berusaha mencari solusi dari permasalahan ini mulai dari perbaikan sistem pasien yang akan dirujuk, membuat ruang transit untuk pasien yang menunggu kamar tetapi yang tidak membutuhkan observasi ketat khususnya pasien level 3 dan 4 serta terobosan terbaru membuat discharge louge yang sudah diberlakukan mulai pertengahan bulan Mei 2016.

Beberapa kebijakan yang dikeluarkan cukup membatu mengatasi waktu tunggu pindah (boarding time) pasien di IGD, tetapi mengingat situasi IGD yang tidak bisa diprediksi tentunya kebijakan terhadap ketenagaan serta ketersediaan fasilitas juga harus diperhitungkan mengingat beban kerja yang melebihi akan berdampak terhadap konsentrasi kerja yang nantinya akan berpengaruh terhadap keselamatan pasien dan pekerja itu sendiri. 
Peningkatan kemampuan sumber daya termasuk staf perawat IGD tentang perawatan pasien post resusitasi, perlu mendapatkan perhatian karena tidak semua staf memiliki kompetensi yang sama. Ketersediaan fasilitas terutama Ruang intensive Care Unit (ICU) memiliki peranan penting untuk mengurangi waktu tunggu pindah (boarding time) pasien di IGD mengingat kondisi pasien post resusitasi di IGD akan mendapatkan pengawasan yang lebih intensive di ruang ICU sehingga pasien yang mempunyai harapan hidup tinggi bisa terselamatkan.

Situasi IGD yang penuh sesak akibat dari ketidaksesuaiannya antara ketersediaan sumber daya dan permintaan pasien memiliki dampak terhadap kualitas dan kekurangan waktu merawat pasien sehingga menyebabkan kondisi pasien semakin memburuk bahkan terjadi kematian (Forero \& Hillman, 2011). Pada kenyataannya, banyak hal yang menyebabkan terjadinya kematian pada pasien trauma level 1 dan 2 , selain akibat dari waktu tunggu pindah (boarding time) pasien ke ruang intensif, seperti kondisi pasien yang bertambah buruk setelah dilakukan resusitasi serta tingkat komplikasi pasien yang tinggi. Hal lain tersebut tidak dibahas dalam penelitian ini.

Keterbatasan pada penelitian ini adalah pada saat pengambilan data, peneliti belum mengelompokan pasien dalam kategori umur yang sama sehingga mendapatkan hasil yang lebih representatif terhadap penyebab kematian pasien.

\section{SIMPULAN}

Waktu tunggu pindah (boarding time) pasien trauma level 1 dan 2 sebagian besar $>2$ jam, yaitu sebanyak 23 orang $(56,1 \%)$. Kejadian kematian pada pasien trauma level 1 dan 2 sebagian besar terjadi, yaitu sebanyak 22 orang $(53,7 \%)$.
Berdasarkan hasil uji chi-square didapatkan $X^{2}$ hitung $=5,331, \alpha=0,021$ yang menyatakan bahwa ada hubungan waktu tunggu pindah (boarding time) pasien trauma level 1 dan 2 dengan kejadian kematian, arah korelasi positif. Hal ini menunjukkan bahwa semakin lama waktu tunggu pindah (boarding time) pasien trauma level 1 dan 2, maka semakin tinggi kejadian kematiannya. Besarnya risiko kematian pada pasien trauma level 1 dan 2 yang memiliki waktu tunggu pindah (boarding time) >2 jam sebesar 4,571 kali lipat. Setidaknya pasien trauma level 1 dan 2 yang memiliki waktu tunggu pindah (boarding time) >2 jam, sekurang-kurangnya memiliki risiko kematian sebesar 1,089 kali lipat dan paling besar berisiko kematian sebesar 17,157 kali lipat.

Saran untuk manajemen pelayanan RSUP Sanglah Denpasar agar lebih meningkatkan perhatian terhadap pasien yang memiliki boarding time $>2$ jam dengan memberikan penandaan "BOARDING" pada sampul luar catatan medik (CM) pasien yang sudah dinyatakan rawat inap dan meningkatkan kemampuan perawat IGD dengan inhouse training tentang perawatan intensif pasien post resusitasi sehingga meningkatkan kualitas pelayanan di IGD terutama pasien trauma level 1 dan 2 post resusitasi. Bagi Institusi pendidikan agar menyediakan waktu yang representatif dalam hal pemberian materi pelajaran manajemen keperawatan gawat darurat khususnya terkait dengan waktu tunggu pindah (boarding time) pasien di IGD dan angka mortalitas pasien emergency. Bagi peneliti selanjutnya agar mengembangkan penelitian ini lebih lanjut dengan metode prospective clinical trial, dengan melakukan pengambilan sampel secara acak pada katagori umur yang spesifik terhadap semua pasien IGD yang memiliki waktu tunggu pindah (boarding time) lebih dari 2 jam sesuai SPO yang ada sehingga 
bisa menentukan secara pasti penyebab kematian yang terjadi. Penelitian ini juga bisa dikembangkan melalui study kualitatif.

\section{DAFTAR PUSTAKA}

Damayanti, P., Sutono, \& Darsih. (2017). Faktor-faktor yang berisiko Terjadinya Pasien Stagnan di Instalasi Gawat Darurat Rumah Sakit Umum Pusat Dr. Sardjito Yogyakarta. Junal Keperawatan Klinis dan Komunitas, 1(2): 81-89.
Forero, R. \& Hillman. 2008. Access Block and Overcrowding: A Literature Review. Simpson Centre for Health Services Research, University of New South Wales.

Singer, A. J., Thode, H. C. J., Viccellio, P., \& Pines, J. M. 2011. The Association Between Length of Emergency Departement Boarding and Mortality. Academic Emergency Medicine 18 (12): 1324-1329. 
Tabel 1. Karakteristik Responden

\begin{tabular}{|c|c|c|c|}
\hline No & Karakteristik & Frekuensi (f) & Persentase $(\%)$ \\
\hline \multirow[t]{3}{*}{1} & Jenis kelamin: & & \\
\hline & Laki-laki & 29 & 70,7 \\
\hline & Perempuan & 12 & 29,3 \\
\hline \multirow[t]{3}{*}{2} & Level Triage: & & \\
\hline & Level 1 & 22 & 53,7 \\
\hline & Level 2 & 19 & 46,3 \\
\hline \multirow[t]{7}{*}{3} & Jenis trauma: & & \\
\hline & Trauma kepala & 30 & 73,2 \\
\hline & Trauma dada & 2 & 4,9 \\
\hline & Trauma abdomen & 2 & 4,9 \\
\hline & Trauma muskuloskeletal & 1 & 2,4 \\
\hline & Trauma spinal & 4 & 9,8 \\
\hline & Trauma thermal & 2 & 4,9 \\
\hline \multirow[t]{3}{*}{4} & $\begin{array}{l}\text { Waktu tunggu pindah } \\
\text { (boarding time) pasien } \\
\text { trauma level } 1 \text { dan } 2 \text { : }\end{array}$ & & \\
\hline & $\leq 2 \mathrm{jam}$ & 18 & 43,9 \\
\hline & > 2 jam & 23 & 56,1 \\
\hline \multirow[t]{3}{*}{5} & Kejadian kematian & & \\
\hline & Tidak & 19 & 46,3 \\
\hline & Ya & 22 & 53,7 \\
\hline
\end{tabular}


Tabel 2. Hasil Uji Statistik Chi-Square Hubungan waktu tunggu pindah (boarding time) pasien trauma level 1 dan 2 dengan kejadian kematian di Triage Bedah IGD RSUP Sanglah Tahun 2016

\begin{tabular}{|c|c|c|c|c|c|c|c|}
\hline & & \multicolumn{4}{|c|}{ Kejadian Kematian } & \multicolumn{2}{|c|}{ Total } \\
\hline & & \multicolumn{2}{|c|}{ Tidak } & \multicolumn{2}{|c|}{$\mathrm{Ya}$} & \multirow[b]{2}{*}{ f } & \multirow[b]{2}{*}{$\%$} \\
\hline & & f & $\%$ & f & $\%$ & & \\
\hline \multirow{2}{*}{$\begin{array}{l}\text { Waktu tunggu pindah } \\
\text { (boarding time) pasien } \\
\text { trauma level } 1 \text { dan } 2\end{array}$} & $\leq 2$ jam & 12 & 66,7 & 6 & 33,3 & 18 & 43,9 \\
\hline & $>2$ jam & 7 & 30,4 & 16 & 69,6 & 23 & 56,1 \\
\hline Total & & 19 & 46,3 & 22 & 53,7 & 41 & 100 \\
\hline
\end{tabular}

Tabel 3. Hasil Odds Ratio Hubungan waktu tunggu pindah (boarding time) pasien trauma level 1 dan 2 dengan kejadian kematian di Triage Bedah IGD RSUP Sanglah Tahun 2016

\begin{tabular}{lccc}
\hline & & \multicolumn{2}{c}{ 95\% Confidence Interval } \\
\cline { 3 - 4 } & Value & Lower & Upper \\
\hline Odds Ratio for waktu (<=6 Jam / > 6 Jam) & 4.571 & 1.218 & 17.157 \\
\hline For cohort mati = Tidak Mati & 2.190 & 1.089 & 4.406 \\
\hline For cohort mati = Mati & .479 & .236 & .972 \\
\hline N of Valid Cases & 41 & & \\
\hline
\end{tabular}

